\title{
Turbulence observations in the Gulf of Trieste under moderate wind forcing and different water column stratification
}

\author{
Francesco Marcello Falcieri ${ }^{1}$, Lakshmi Kantha ${ }^{1,2}$, Alvise Benetazzo ${ }^{1}$, Andrea Bergamasco ${ }^{1}$, Davide Bonaldo ${ }^{1}$, \\ Francesco Barbariol ${ }^{1}$, Vlado Malačič ${ }^{3}$, Mauro Sclavo ${ }^{1}$, and Sandro Carniel ${ }^{1}$ \\ ${ }^{1}$ Istituto di Scienze Marine - Consiglio Nazionale delle Ricerche, Venice, Italy \\ ${ }^{2}$ Colorado Center for Astrodynamical Research - University of Colorado, Boulder, CO, USA \\ ${ }^{3}$ National Institute of Biology, Marine Biology Station, Piran, Slovenia \\ Correspondence to: Francesco Marcello Falcieri (francesco.falcieri@ve.ismar.cnr.it)
}

Received: 17 July 2015 - Published in Ocean Sci. Discuss.: 14 August 2015

Revised: 21 December 2015 - Accepted: 17 February 2016 - Published: 11 March 2016

\begin{abstract}
The oceanographic campaign CARPET2014 (Characterizing Adriatic Region Preconditionig EvenTs), (30 January-4 February 2014) collected the very first turbulence data in the Gulf of Trieste (northern Adriatic Sea) under moderate wind (average wind speed $10 \mathrm{~m} \mathrm{~s}^{-1}$ ) and heat flux (net negative heat flux ranging from 150 to $400 \mathrm{~W} \mathrm{~m}^{-2}$ ). Observations consisted of 38 CTD (Conductivity, Temperature, Depth) casts and 478 microstructure profiles (grouped into 145 ensembles) with three sets of yoyo casts, each lasting for about 12 consecutive hours. Averaging closely repeated casts, such as the ensembles, can lead to a smearing effect when in the presence of a vertical density structure with strong interfaces that can move up or down between subsequent casts under the influence of tides and internal waves. In order to minimize the smearing effect of such displacements on mean quantities, we developed an algorithm to realign successive microstructure profiles to produce sharper and more meaningful mean profiles of measured turbulence parameters.

During the campaign, the water column in the gulf evolved from well-mixed to stratified conditions due to Adriatic waters intruding at the bottom along the gulf's south-eastern coast. We show that during the warm and relatively dry winter, the water column in the Gulf of Trieste, even under moderate wind forcing, was not completely mixed due to the influence of bottom waters intruding from the open sea. Inside the gulf, two types of water intrusions were found during yoyo casts: one coming from the northern coast of the Adriatic Sea (i.e. cooler, fresher and more turbid) and one coming from the open sea in front of the Po Delta (i.e. warmer,
\end{abstract}

saltier and less turbid). The two intrusions had different impacts on turbulence kinetic energy dissipation rate profiles. The former, with high turbidity, acted as a barrier to winddriven turbulence, while the latter, with low sediment concentrations and a smaller vertical density gradient, was not able to suppress downward penetration of turbulence from the surface.

\section{Introduction}

Turbulence and associated processes are gaining a broader interest within the ocean sciences community for their fundamental role in many ocean phenomena (Gargett, 1997; Thorpe, 2005). Because of their importance in issues such as ocean mixing, energy transfer, dissipation or dispersion of nutrients and pollutants, a better understanding of turbulent processes is paramount for ocean sciences. While turbulence observations have become more common in recent years there is still a need to collect more data sets for use in the analysis of mixing in the water column, and to improve turbulent mixing parametrization in numerical ocean models (Carniel et al., 2012).

The Gulf of Trieste (GoT henceforth) is a small and shallow bay (maximum depth less than $30 \mathrm{~m}$ ) located in the north-eastern corner of the Adriatic Sea (Fig. 1). It is generally classified as a region of freshwater influence (ROFI; Simpson et al., 1993) due to intense riverine discharges and undergoes a marked seasonal variability. The GoT hydrodynamics are driven by winds (Bora and Sirocco), tides, buoy- 


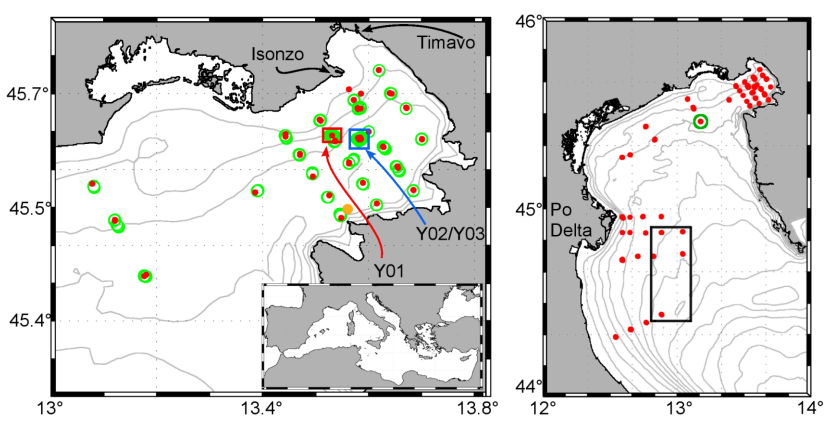

Figure 1. (Left panel) location of the CARPET2014 stations inside the GoT. Red dots denote CTD stations; green circles MSS stations, red and blue squares MSS yoyo sites from Y01 and Y02/Y03, respectively, yellow dot points out the VIDA buoy. The insert shows the location of the Adriatic Sea inside the Mediterranean Sea. (Right panel) stations of the entire CARPET2014 cruise. Red dots show locations of CTD casts, black rectangle marks the area of the CTD casts considered representative of open-sea waters (see Fig. 4), the green circle shows the station used as $\mathrm{Y} 02$ and $\mathrm{Y} 03$ casts end points.

ancy effects of the Isonzo River plume and exchanges of water masses with the Adriatic Sea. The north-easterly Bora generates a cyclonic circulation in the northern Adriatic and pushes surface waters out of the GoT, inducing a compensating inflow of open-sea waters near the bottom (Malačič et al., 2012). The inflow/outflow transport is governed by topographic control of the wind-driven circulation (Csanady, 1982). During Sirocco winds, however, the water masses at the surface are driven to the northern shore of the Adriatic Sea between Venice and Trieste, where they bifurcate in front of the GoT. The eastern part of the flow turns right and enters the GoT along its northern coastline, while the western part turns left and contributes to the coastal current flowing towards the Venice lagoon (Malačič et al., 2012).

The Isonzo River plume, during windless conditions, occupies the surface of the northern GoT with inertial motions near the river outlet, while along the frontal line that embraces the plume's bulge there is a quasi-geostrophic motion with a convergence zone (Malačič et al., 1996). Due to vertical mixing of the surface fresh water with seawater across the halocline, this plume induces an inflow of water masses near the bottom of the GoT (Malačič and Petelin, 2001). The annual mean flow rate of the Isonzo River was about $90 \mathrm{~m}^{3} \mathrm{~s}^{-1}$ from 1998 to 2005 (Comici and Bussani, 2007), but different estimates, varying by a factor of 3 from this value, can also be found in the literature. In January-February, the monthly mean flow rate ranged from 1 to $351 \mathrm{~m}^{3} \mathrm{~s}^{-1}$, with $41 \mathrm{~m}^{3} \mathrm{~s}^{-1}$ on average (Comici and Bussani, 2007) during the 19982005 period. In 2014, the Isonzo River experienced a period of strong discharges, with February 2014 average discharge rising to $547 \mathrm{~m}^{3} \mathrm{~s}^{-1}$. During the sampling period inside the GoT, the mean discharge was $868 \mathrm{~m}^{3} \mathrm{~s}^{-1}$ with maximum and minimum values of 1768 and $327 \mathrm{~m}^{3} \mathrm{~s}^{-1}$, respectively (according to data collected from the hydro-meteorological service of Friuli-Venezia Giulia, Servizio Idrometeorologico - Protezione Civile Friuli Venezia Giulia). Those unusually large discharge rates have an effect on the surface density structure, which in turn affects near-surface turbulence characteristics.

Turbulence measurements in the Adriatic Sea are scarce and scattered. To our knowledge, a very limited number of papers dealing with this topic have been published in the literature. Peters and Orlić (2005) presented the first measurements of turbulence in the Adriatic Sea with a set of 32 casts in the central basin collected in May 2003 within the framework of the DOLCEVITA (Dynamics of Localized and Eddy Variability in the Adriatic) project. During the collection period, wind forcing was weak and the water column generally well stratified with a shallow mixed-layer depth. The authors found small values for the turbulent kinetic energy (TKE) dissipation rates in the upper mixed layer. Peters et al. (2007) reported a second set, collected in February 2003 also within the DOLCEVITA project in the shallow northern Adriatic under strong winds, intense cooling and a well-mixed water column. Their main findings highlight different contributions of surface forcing and bottom friction on the TKE dissipation rate profiles. At both study sites, the main contribution to turbulence generation was found to be mechanical and buoyancy effects were small.

Carniel et al. (2008) discussed two sets of repeated observations in the southern Adriatic Sea in front of the Gargano peninsula during the March 2006 DART06A (Dynamics of the Adriatic in real time) cruise. Their study revealed layered thermohaline staircase structures that originated from double diffusive convection. During the DART06B cruise (August 2006), Carniel et al. (2012) collected a total of more than 300 casts, which allowed them to describe the upper oceanic mixed layer under a series of different meteorological conditions (different wind forcing, night-time convection and strong insolation).

All of the studies cited above deal almost exclusively with the surface mixed layer and only Peters et al. (2007) discuss the role of the bottom boundary on turbulent dissipation rates. This means that the interaction between surface and bottom turbulence has only been described briefly in the Adriatic Sea.

In this study a sub-set of observations will be described, which were collected during the CARPET2014 (Characterizing Adriatic Region Preconditionig EvenTs) campaign onboard the R/V Urania in the northern Adriatic Sea between 29 January and 10 February.

\section{Observations and data processing}

The CARPET2014 data set (Benetazzo et al., 2015) was collected between 30 January and 10 February 2014 in the northern Adriatic Sea. In this work only the data collected inside the GoT will be discussed (Fig. 1). 
Table 1. Specifics of each yoyo set. Times are in UTC.

\begin{tabular}{lllll}
\hline Set & Starting time & Ending time & $\begin{array}{l}\text { Ensembles } \\
\text { (casts })\end{array}$ & Intervals \\
\hline Y01 & $30 / 01 / 201520: 50$ & $31 / 01 / 201502: 30$ & $11(54)$ & $30 \mathrm{~min}$ \\
Y02 & $01 / 02 / 201514: 00$ & $02 / 02 / 201501: 40$ & $12(36)$ & $30 \mathrm{~min}$ \\
Y03 & $03 / 02 / 201515: 50$ & $04 / 02 / 201504: 11$ & $27(87)$ & $15-30 \mathrm{~min}$
\end{tabular}

Turbulence measurements were made with two microstructure profilers (MSS 90; Prandke et al., 2000), which were allowed to free fall until they hit the sea floor. This operational procedure permitted collection of observations very close $(8 \mathrm{~cm}$ from the bottom) to the sea floor. During the cruise, 818 casts were made at 104 stations, 554 with a MSS profiler owned by ISMAR-CNR (Istituto di Scienze Marine Consiglio Nazionale delle Ricerche) and 264 with one owned by the Slovenian National Institute of Biology (NIB-MBP, National Institute of Biology - Marine Biology Station Piran). At each station, three to five profiles were measured, which were then averaged to obtain a mean profile representative of the water column during sampling. We will refer to these profiles as ensemble casts.

Among all the stations, three were in yoyo mode, i.e. a series of repeated casts in a fixed location with the $\mathrm{R} / \mathrm{V}$ either at anchor or keeping the position dynamically. A yoyo series is helpful in studying the temporal evolution of the water column at a given location, but at the loss of synoptic and spatial information. The three yoyo casts (Y01, Y02 and Y03) were made at two stations close to each other in the deepest part of the GoT (blue squares in right panel of Fig. 1) with a sampling rate of $30 \mathrm{~min}$ (specifics of each set are reported in Table 1). During the last part of Y03, the sampling rate was increased to every $15 \mathrm{~min}$.

The temperature and salinity measurements from the two MSS probes were calibrated against CTD (Conductivity, Temperature, Depth) observations by pairing the first cast of each MSS ensemble to its spatially and temporally closest CTD. Of all possible pairings, only those that were closer than $1000 \mathrm{~m}$ and taken less than $15 \mathrm{~min}$ apart were considered. In order to have an optimal cross-calibration, all profiles with a stratified water column were ignored (i.e. those profiles that presented a salinity range higher than 0.3 or a temperature range higher than $0.5^{\circ} \mathrm{C}$ ). This was necessary because in the presence of a thermocline or halocline, even a small vertical displacement (due to interface oscillations) between casts could result in measures of different values at the same depths and hence errors in calibration.

The bias, root mean squared error (RMSE) and percentage root mean squared error (PRMSE) of each pair were computed, and all profiles with PRMSE less than $1 \%$ were used to compute each sensor bias. Results are shown in Table 2.

Among all the profiles collected by the ISMAR probe, 73 pairs satisfied the spatial and temporal proximity criteria and
21 were selected for cross-calibration based on vertical stratification criteria. The NIB probe had 60 pairs, with 28 of those eligible for calibration. For all profiles the bias and RMSE are very low, almost at the precision limit of each sensor, and PRMSE values are therefore small. The only sensor that shows a significant BIAS $(-0.2418)$ is the salinity sensor on the ISMAR profiler, which was therefore corrected for later computations.

The two microstructure profilers acquired data at $1024 \mathrm{~Hz}$ to allow for the collection of observations every $0.0011 \mathrm{~m}$ (given an average fall speed of $0.6 \mathrm{~m} \mathrm{~s}^{-1}$ ). Both probes were equipped with a standard CTD sensor (pressure, temperature and conductivity), two shear sensors and a fast temperature for the water column microstructure. Shear data from both profilers were used to determine the turbulent kinetic energy dissipation rate using (Gregg, 1987; Peters et al., 2007)

$\varepsilon=7.5 v\left(\frac{\mathrm{d} u}{\mathrm{~d} z}\right)^{2}$,

where $\mathrm{d} u / \mathrm{d} z$ is the velocity shear and $v$ is the kinematic viscosity. Details of the protocol used for data processing can be found in Prandke et al. (1998); the algorithm used to minimize the smearing effect of interface observations is given in Appendix A.

In addition to the microstructure profiles, ancillary observations include 104 CTD, current measurements made with a downward looking hull-mounted ADCP (Acoustic Doppler Current Profiler, RDI workhorse $75 \mathrm{KHz}$ ), acoustic bin size set to $4 \mathrm{~m}$ with a blank interval of $5 \mathrm{~m}$ and first bin centred at $7 \mathrm{~m}$ ), and meteorological forcing acquired by the R/V Urania weather station and by the Slovenian coastal observatory VIDA buoy. During selected periods 3-D sea-surface wave-field measurements were made with a Wave Acquisition Stereo System (WASS; Benetazzo et al., 2012) mounted on the port side of the R/V bridge about $8 \mathrm{~m}$ above mean sea level.

\subsection{Meteorological conditions and surface forcing}

Compared to the climatological mean, the winter of 20132014 can be considered dry and warm, with January 2014 and the period of the CARPET2014 cruise being anomalously warm and moist. During the campaign, a warm and moist air mass was flowing from the south-east (northern African coast) over the northern Adriatic region while, at the 
Table 2. Bias, root mean square error (RMSE) and percent RMSE computed for the ISMAR and NIB MSS probes compared to CTD measurements.

\begin{tabular}{lrrr}
\hline & Bias & RMSE & PRMSE \\
\hline ISMAR - Temperature & 0.0046 & 0.0205 & 0.1932 \\
ISMAR - Salinity & -0.2418 & 0.2424 & 0.6517 \\
NIB - Temperature & -0.0072 & 0.0280 & 0.2530 \\
NIB - Salinity & 0.030 & 0.2227 & 0.0607 \\
\hline
\end{tabular}

same time, a cold air mass was flowing from the eastern part of the European continent towards the northern Adriatic Sea.

Atmospheric data, sea-surface temperature and salinity were recorded throughout the cruise by the R/V Urania's ship-borne weather station (located about $10 \mathrm{~m}$ a.s.l.) and by a thermistor and a salinometer mounted on the R/V's hull, about $2 \mathrm{~m}$ b.s.l. (Fig. 2, left panel). The latter had a bias of 0.2 when compared to CTD data and hence its measurements used for computation of fluxes were corrected accordingly. The R/V Urania sailed in the GoT and did not hold a fixed position, and therefore, in order to have a complete representation of the atmospheric conditions, the shipborne weather observations need to be supplemented by a fixed observation point. Data collected from the Slovenian coastal observatory VIDA were also used for computation of fluxes (Fig. 2, right panel). The VIDA buoy is anchored at a depth of $22 \mathrm{~m}$ about $2.3 \mathrm{~km}$ off the coast in front of Piran (https://www.nib.si/mbp/en/buoy/general). Atmospheric observations and fluxes computed using the two data sets show strong similarity, and therefore their merged analysis can be considered to be representative of the atmospheric conditions over the whole GoT during the campaign. The smallscale variations in R/V Urania's data set can be ascribed to a higher sampling rate (one record per minute) with averages over $10 \mathrm{~min}$ intervals used for flux computations, compared to the $30 \mathrm{~min}$ averages for the VIDA buoy data set.

At the beginning of observations, easterly Bora was turning to a south-east Sirocco $\left(\sim 10 \mathrm{~m} \mathrm{~s}^{-1}\right)$ that lasted for 2 days until the night of 2 February, when it turned back to a Bora with an average wind speed of $10 \mathrm{~m} \mathrm{~s}^{-1}$ with peaks of $16 \mathrm{~m} \mathrm{~s}^{-1}$ (Fig. 2b); during the Sirocco event, three calm periods were recorded with weak winds from the north. Air temperature showed a similar pattern with lower values during Bora (between 5 and $8^{\circ} \mathrm{C}$ ) and a warmer one during Sirocco (up to $14.5^{\circ} \mathrm{C}$ ). The three calm periods can also be seen in air temperature, with sudden drops of about $5^{\circ} \mathrm{C}$. Throughout the cruise, sea-surface temperature was rather constant around $11.5^{\circ} \mathrm{C}$ with an increasing trend toward the end of the operations (Fig. 2a). The ship-borne observations showed a stronger variability with respect to the VIDA ones due to the R/V's positional changes within the GoT. Analogous behaviour was also seen in sea-surface salinity (not shown).
Figure 2 also shows the heat fluxes (panel c) and wind stress (panel d in cyan) computed using the COARE algorithm (Coupled Ocean-Atmosphere Response Experiment; Fairall et al., 2003), from on-site observations (sea-surface temperature and salinity, air temperature, pressure and humidity) and from short- and long-wave radiation. The radiation fields were derived from an implementation of the Coupled Ocean Wave and Sediments model over central Europe with a $7 \mathrm{~km}$ horizontal resolution (Ricchi et al., 2016).

The net heat flux was always negative at both sites, with a heat loss from the ocean to the atmosphere always higher than $150 \mathrm{~W} \mathrm{~m}^{-2}$ during Bora events (peaks of just over $400 \mathrm{~W} \mathrm{~m}^{-2}$ at Urania and $350 \mathrm{~W} \mathrm{~m}^{-2}$ at VIDA). During Sirocco events, fluxes were generally smaller, with heat losses of around $100 \mathrm{~W} \mathrm{~m}^{-2}$. It is noteworthy that on the one hand the latent heat flux was always negative, but on the other hand, sensible heat flux turned positive during Sirocco due to air temperature being higher than the sea-surface temperature. During the three calm periods, a drop in wind speed and air temperature, below the sea-surface temperature, resulted in a switch in the sensible heat flux direction.

The buoyancy flux at the surface (Fig. 2d) was obtained following Shay and Gregg $(1984,1996)$ as

$$
J_{\mathrm{b}}=\frac{g}{\rho_{\mathrm{w}}}\left\{\frac{\alpha}{C_{\mathrm{p}}} J_{\mathrm{t}}+\frac{\beta S}{L_{\mathrm{E}}(1-S)} J_{1}\right\}
$$

where the first term inside brackets represents the heat buoyancy flux, computed from the net heat flux $\left(J_{\mathrm{t}}\right)$, the thermal expansion coefficient $\left(\alpha=-2.16 \times 10^{-4}{ }^{\circ} \mathrm{C}^{-1}\right)$ and the sea water specific heat $\left(C_{\mathrm{p}}=3.98 \times 10^{3} \mathrm{~J} \mathrm{~K}^{-1} \mathrm{~kg}^{-1}\right)$; the second term is the evaporative buoyancy flux computed from the latent heat flux $\left(J_{1}\right)$, the haline contraction coefficient $(\beta=$ $0.79)$, the latent heat of evaporation $\left(L_{\mathrm{E}}=2.6 \times 106 \mathrm{~J} \mathrm{~kg}^{-1}\right)$ and sea-surface salinity expressed as concentration. The convention used for heat and buoyancy fluxes in this study is that negative/positive fluxes correspond to losses/gains from/to the ocean to/from the atmosphere. In the case of buoyancy, this means that a negative $J_{\mathrm{b}}$ corresponds to a loss of buoyancy from the ocean to the atmosphere (i.e. water is getting less dense) with a stabilizing effect on the water column, while positive $J_{\mathrm{b}}$ indicates a gain of buoyancy (i.e. water becoming more dense) and hence a destabilizing effect on the water column.

\subsection{Hydrological conditions and water mass structure}

The hydrological conditions in the GoT during CARPET2014 are the result of the forcing described in Sect. 2.1, a combination of wind-driven circulation during the two prevalent winds (Bora and Sirocco), with inertial oscillations in offshore areas during times of wind shifts from one type to another and during periods of calm between windy episodes.

Weather and ship logistical constraints did not permit a synoptic hydrological survey of the entire GoT; hence, different parts of the basin were covered each day. In order to give 

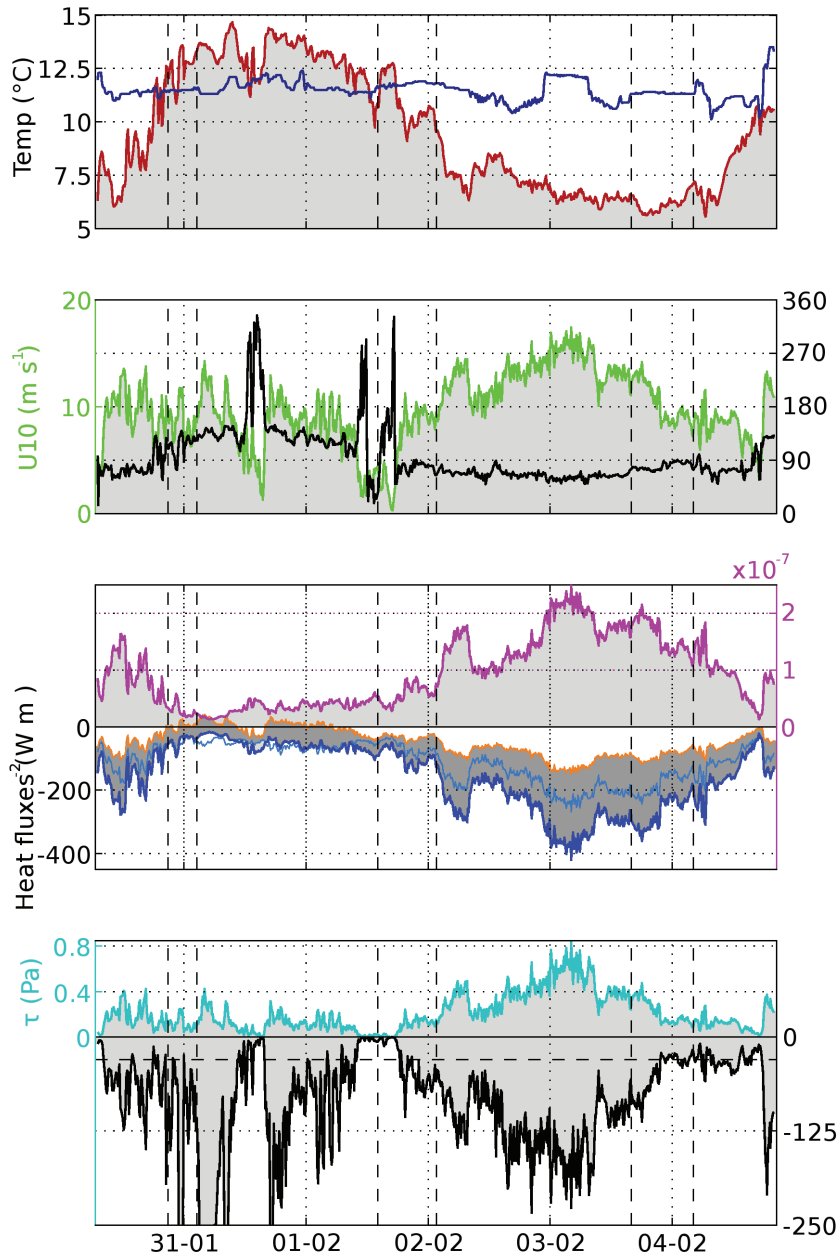

(a)

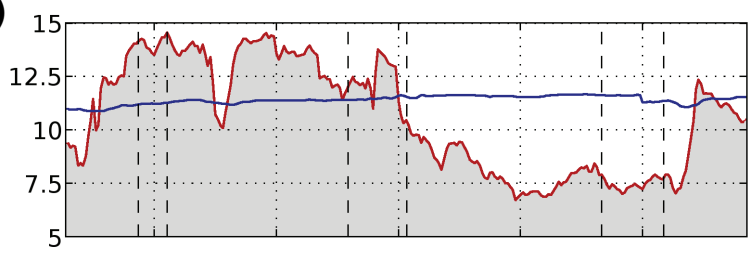

(b)

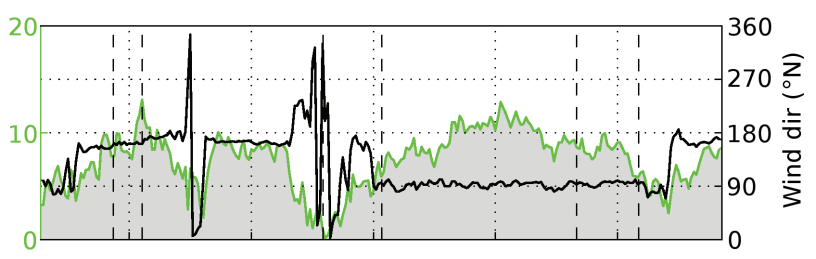

(c)

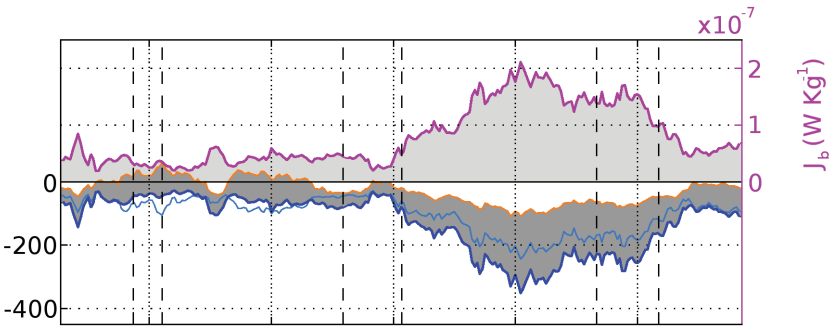

(d)

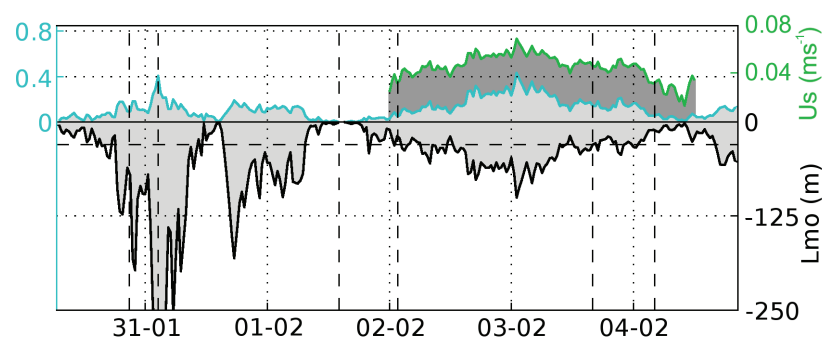

Figure 2. Atmospheric and sea-surface observations and fluxes collected from the R/V Urania (left panels) and VIDA buoy (right panels). (a) Air (red) and sea (blue) temperature time series; (b) wind speed (light green) and wind direction (black); (c) net (blue line), latent (light blue) and sensible (orange) heat fluxes computed with the COARE algorithm and buoyancy flux (magenta); (d) wind stress (cyano), MoninObukhov length (black) and Stokes drift (dark green). Given that the maximum depth of the GoT is $25 \mathrm{~m}, L_{\mathrm{mo}}$ is shown up to $-250 \mathrm{~m}$ depth to provide a clearer representation of the water column. $L_{\text {mo }}$ values can be as low as $-1200 \mathrm{~m}$ during calm periods. Vertical dashed lines show the yoyo cast collection time.

a rough overview of the hydrodynamics of the GoT, surface (from 0 to $2.5 \mathrm{~m}$ ) and bottom (last $2.5 \mathrm{~m}$ of cast) temperature and salinities collected on 30 and 31 January, as well as 4 February from CTD casts, are shown in Fig. 3 along with the bottom currents measured by the hull-mounted ADCP.

The overall picture that emerges from Fig. 3 is a bottom circulation with waters incoming from the open sea along the south-eastern coast and flowing out along the north-western coast (left panels). The same pattern is common to both tidal intervals, during rising (blue arrows in Fig. 3 left panels) and falling (blue arrows in Fig. 3, left panels) tides, with the latter showing weaker currents. The intervals of rising and falling tides have been defined from the pressure values recorded by the bottom-mounted ADCP located at the VIDA buoy. The apparently incoherent vectors close to the coast can be explained by the influence of the coastline and the shallow topography on the local currents. Each plot shows a $24 \mathrm{~h} \mathrm{col}-$ lection of data over a relatively small area, and may also include small-scale variations.

Temperature and salinity distributions (Fig. 3) are in agreement with the general picture of warmer and saltier bottom waters entering the southern part of the GoT and cooler and fresher waters confined to the northern part. The low surface salinity values in the northernmost part and in front of Trieste (Fig. 3, right panels) are the result of the influence of the Isonzo and Timavo discharges (Fig. 1, left panel), respectively. It is of interest that on 4 February, the easternmost stations were warmer and saltier throughout the water column than those on 30 January. This cooling of the water column 

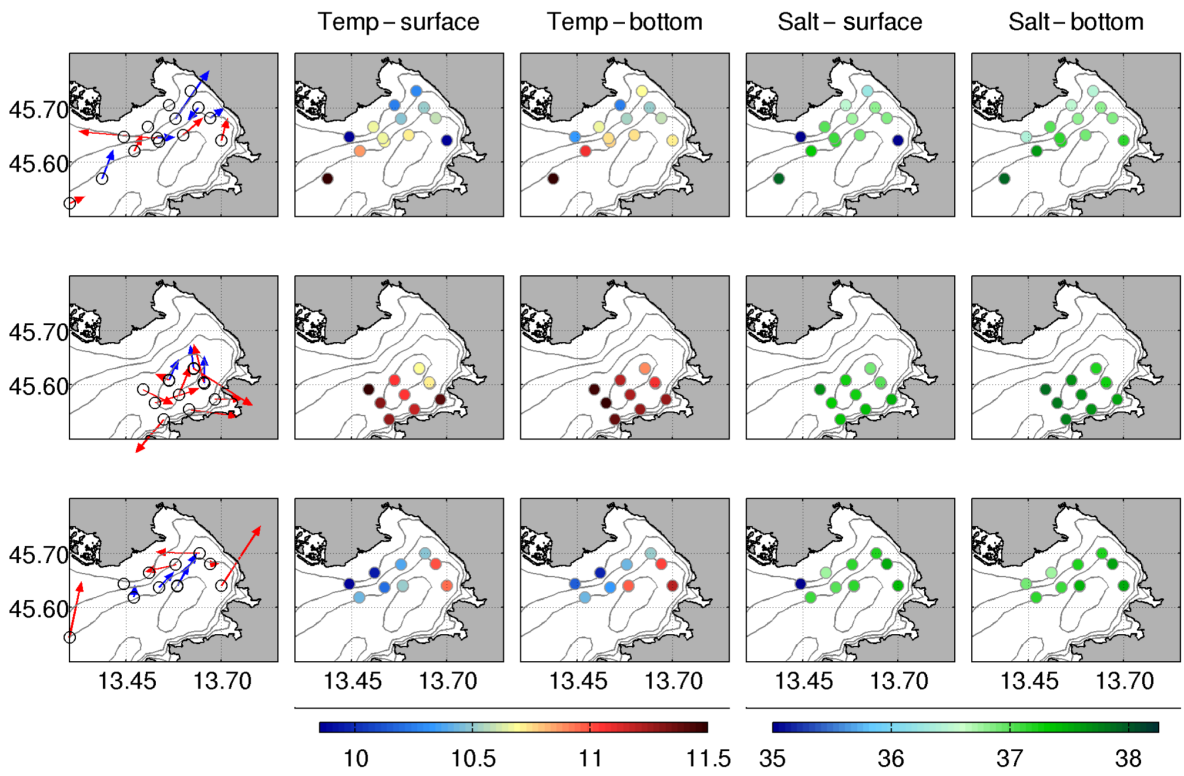

Figure 3. Bottom currents and values from CTD casts at surface and bottom are shown inside the GoT for 30 January (top panels), 31 January (central panels) and 4 February (bottom panels). Panels on the left column show the ADCP bottom cell currents; red arrows are observations taken during rising tide, blue arrows during falling tide. Temperature (second and third columns) and salinity (fourth and fifth columns) values are shown for surface $(0$ and $2.5 \mathrm{~m}$ ) and bottom layers (last $2.5 \mathrm{~m}$ of cast) inside the GoT.
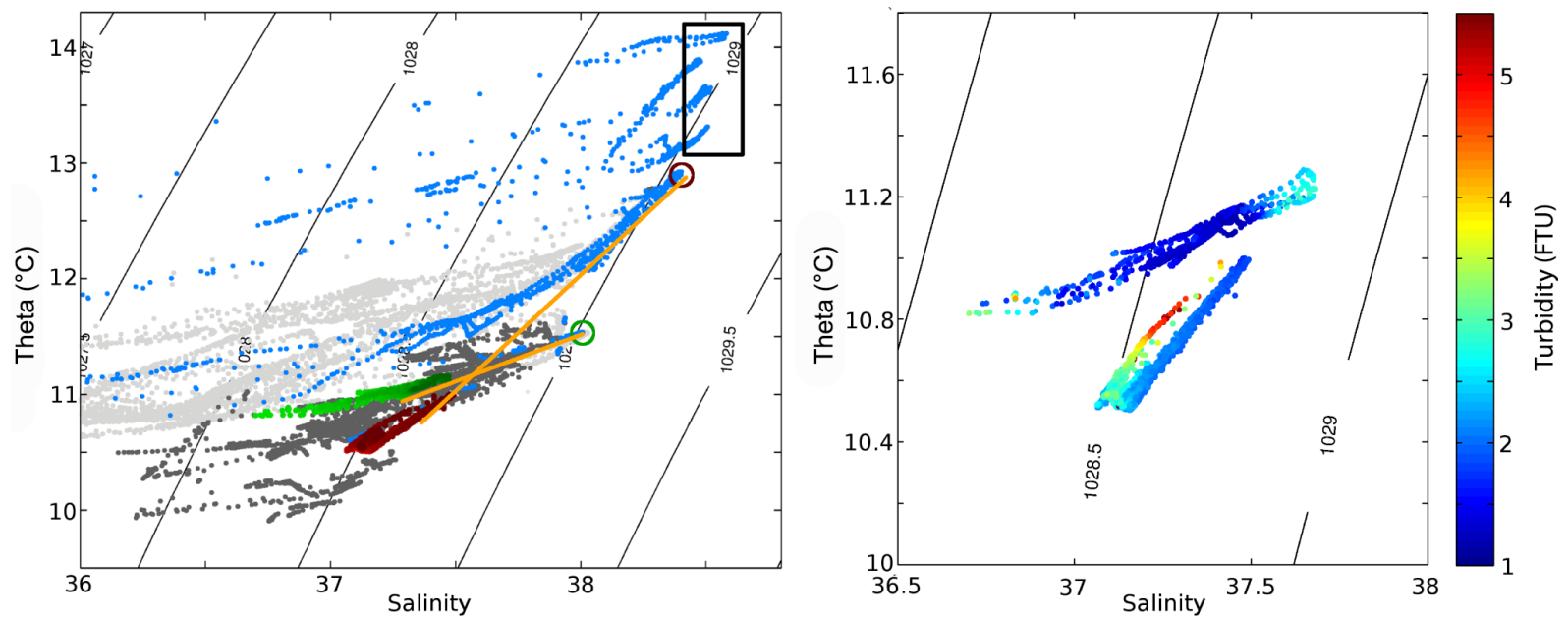

Figure 4. (Left panel) $\theta-S$ plot of all CTDs and MSSs (both ISMAR and NIB) casts (light grey for the northern Adriatic and dark grey for the GoT). The green and red dots are the MSS-ISMAR and MSS-NIB ensemble means for Y02 and Y03, respectively, light colour for surface values and dark colour for bottom ones. The green circle indicates the bottom waters observed at the entrance of the GoT on 30 January that are the end point for Y02 bottom waters; red circles point to deep waters outside the GoT on 4 January considered as the end point of Y03 bottom water. The black square encompasses values in bottom waters in the centre of the North Adriatic Sea. Locations of end points are shown in Fig. 1. The profiles of the cast leading to the end points are shown in light blue. (Right panel) $\theta-S$ plot for Y02 and Y03. Colour scale shows turbidity FTUs (formazin turbidity units) as measured by the back scatterometer mounted on the MSS ISMAR probe.

was due to the steady negative heat flux between Y02 and Y03 (Fig. 2).

The $\theta-S$ (potential temperature-salinity) plot (Fig. 4), computed from both CTD and MSS data, helps in the identification of the water masses that were present in the GoT and in the northern Adriatic Sea during the campaign. Inside the GoT (dark grey dots in Fig. 4), the water temperature was lower than that outside of the basin (light grey dots in Fig. 4), due to the moderate negative net heat flux throughout the cruise (ranging between -150 and $-400 \mathrm{~W} \mathrm{~m}^{-2}$ ) and the shallow bathymetry of the GoT. Apart from the Isonzo River mouth and the inner part of the gulf, salinity values are com- 
parable to (or slightly smaller than) the rest of the Adriatic Sea. By looking at Y02 and Y03 casts (red and green dots), it is possible to highlight the different origins of part of their bottom waters. More specifically, Y02 presents deep waters (dark green in the left panel of Fig. 4), whose $\theta-S$ values are directed towards an end point (green circle in the left panel of Fig. 4, location shown in Fig. 1, right panel) close to the density isoline $1029 \mathrm{~kg} \mathrm{~m}^{-3}$, which is compatible with northern Adriatic coastal waters (i.e. fresher, cooler and more turbid waters) observed right outside the GoT on 30 January. On the other hand, Y03 $\theta-S$ values of bottom waters have an end point (red circle in left panel of Fig. 4, location shown in Fig. 1 right panel) typical of the open basin, slightly warmer, saltier and cleaner waters (Fig. 4, right panel). Moreover, in the case of the Y03 end point, its characteristics are similar to the open-sea bottom waters in front of the Po Delta (black rectangle in the left panel) during periods of low discharges (Falcieri et al., 2013). The slight misalignment of those $\theta-$ $S$ points with respect to the Y03 end point can be explained by their position being close to the influence of the Po River plume. Both end points are located over the same station but were recorded 4 days apart, the first one on 31 January and the second one on 4 February.

The wave field over the GoT was assessed from data collected by the WASS system on the R/V and at the VIDA buoy. A total of four WASS acquisitions, each of roughly 15 min, were collected between 12:05 and 14:32 UTC of 3 February, right before $\mathrm{Y} 03$, and resulted in an average significant wave height $\left(H_{\mathrm{s}}\right)$ of $0.8 \mathrm{~m}$, period $\left(T_{\mathrm{m}}\right)$ of $3.9 \mathrm{~s}$ and wave length of $23 \mathrm{~m}$. During the acquisition the wind forcing was stable, with a mean wind speed of $14 \mathrm{~m} \mathrm{~s}^{-1}$ and direction of about $75^{\circ} \mathrm{N}$ (typical of Bora wind).

To cover a longer part of the study period, the wave and wind data collected at the VIDA buoy were used. The wave spectrum $E(f)$ of each sea state at the buoy was represented by the JONSWAP spectrum (Hasselmann et al., 1973). This assumption is consistent with the spectrum computed from the R/V with the WASS observations. A further verification of this is that the $H_{\mathrm{s}}$ and $T_{\mathrm{m}}$ computed at VIDA with JONSWAP (given the wind speed and fetch length) are close to those directly observed. This spectrum, which models the distribution of wave energy in deep water fetch-limited sea states, was used to compute the Stokes drift $\left(U_{\mathrm{s}}\right)$ following Hasselman (1970) as

$\boldsymbol{U}_{\mathbf{s}}(z)=\int_{0}^{\infty} \frac{1}{g}(2 \pi f)^{3} E(f) \exp \left(-\frac{2}{g}(2 \pi f)^{2} z\right) \boldsymbol{k} \mathrm{d} f$,

where $z$ is the vertical coordinate positive upwards, $g$ the gravitational acceleration, $f$ is the frequency in $\mathrm{Hz}$ and $\boldsymbol{k}$ is the unit vector in the wave propagation direction. During the period under investigation, fetch-limited and deep-water conditions occurred from 2 February 2014 at 00:00 UTC to 4 February 2014 at 12:00 UTC, as moderate and persistent Bora winds were blowing over the Gulf of Trieste (Fig. 2).
A further verification of this approach is given by the fact that the Stokes drift computed from the WASS spectrum $\left(0.06 \mathrm{~m} \mathrm{~s}^{-1}\right)$ is in good agreement with the value computed at VIDA $\left(0.05 \mathrm{~m} \mathrm{~s}^{-1}\right)$ using the JONSWAP spectrum. The $U_{\mathrm{s}}$ time series (dark green line in Fig. 2d, right side) closely follows the wind stress with values ranging from 0.01 to $0.07 \mathrm{~m} \mathrm{~s}^{-1}$.

\section{Turbulence scaling}

Ocean turbulence is generated and enhanced by different processes such as the shear stress at the sea surface or the bottom, buoyancy fluxes and unstable stratification, breaking and motion of surface and internal waves and wave-current interactions (Burchard et al., 2008; Thorpe, 2005; Kantha and Clayson, 2004). In this study the observed TKE dissipation rate profiles will be compared to their forcing with a similarity scaling approach (Peters et al., 2007) to highlight discrepancies between the theoretical and the observed profiles, identify the dominant forcing and show the role of buoyancy interfaces in suppressing turbulence in the water column.

Turbulence generated by surface wind stress obeys a law of the wall scaling below the wave-influenced surface region (D'Asaro, 2014; Thorpe, 2005) as

$\varepsilon_{\mathrm{s}}=\frac{u_{*}^{3}}{k|z|}$,

where $k=0.4$ is the von Kàrmàn constant, $z$ is the distance from the sea surface and $u_{*}$ is the friction velocity given by

$u_{*}=\left(\frac{\tau_{\mathrm{a}}}{\rho}\right)^{\frac{1}{2}}$

where $\tau_{\mathrm{a}}$ is the wind stress computed with the COARE algorithm from wind speed at $10 \mathrm{~m}$ height and $\rho$ is the surface water density computed from the R/V's hull-mounted instruments. This scaling is valid for the surface layer either under calm sea conditions or below a depth at which turbulence generation by wave breaking or wave-current interactions becomes insignificant (Burchard et al., 2008; Thorpe, 2005).

The law of the wall approach is also valid for turbulence generated by bottom shear stress above a few centimetres thick viscous layer. As for the wind stress-generated turbulence, the TKE dissipation rate near the sea floor can be scaled as

$\varepsilon_{\mathrm{b}}=\frac{u_{* \mathrm{~b}}^{3}}{k|h|}$,

where $h$ is the distance from the sea floor and $u_{* \mathrm{~b}}$ the bottom friction velocity given by

$u_{* \mathrm{~b}}=\left(\frac{\tau_{\mathrm{b}}}{\rho}\right)^{1 / 2}$ 
in which the bottom shear stress $\left(\tau_{* \mathrm{~b}}\right)$ is computed with a non-linear function of the depth-averaged velocity with a quadratic bottom drag law computed as

$\tau_{\mathrm{b}}=\rho C_{\mathrm{D}} u^{2}$,

where $\rho$ is the local water density, $u$ the average bottom current speed as recorded by the downward looking ADCP and $C_{\mathrm{D}}=0.003$ is the bottom drag coefficient (Peters et al., 2007). In the case of Y02 and Y03, current observations are the average of the cells that span from 13 to $17 \mathrm{~m}$ depth, roughly $8 \mathrm{~m}$ above the sea floor. Hence, the bottom stress here computed needs to be regarded as just a rough estimation.

It is common to assume that the dissipation rate due to buoyancy in the surface mixed layer is uniform and equal to $\varepsilon_{\mathrm{b}}=c J_{\mathrm{b}}$. The value of the constant $c$ is trivial to define and different figures have been proposed ranging from $c=0.25$ for the surface upper bound and $c=0.4$ under strong pycnoclines (Kantha, 1980) to $c=0.6$ (Shay and Gregg, 1996; Peters et al., 2007). Here the latter parameterization will be used.

The wave contribution to turbulence in the surface layer is a more complex topic since it consists of three different processes: wave breaking, Stokes production and the development of Langmuir circulation. In the case of wave breaking, the contribution to TKE is generally confined to a depth of the order of the significant wave height and is dissipated rapidly in less than four wave periods (Anis and Moum, 1995; Kantha and Clayson, 2004; Paskyabi and Fer, 2014). Stokes production can be a large contribution to TKE, Kantha (2010; see also Kantha and Clayson, 2004 and Kantha et al., 2010) estimated that its magnitude can be of the same order of conventional shear-generated TKE and can extend deep into the water column where the shear generated by Stokes drift is still significant. Langmuir circulation can extend vertically down to the mixed-layer depth (Grant and Belcher, 2009; Teixeira and Belcher, 2010).

In the collected data set not all the information is available to fully investigate and scale the role of waves in turbulence generation. To give a general description of the relationship between different turbulence forcings, we adopt a regime diagram (Li et al., 2005) as modified by Belcher et al. (2012). The diagram is constructed by plotting the Langmuir number versus the ratio of the buoyancy and wave-forced turbulence. The Langmuir number La (McWilliams et al., 1997) represents the ratio between the wind and wave-forced TKE production and is computed as

$L a=\left(\frac{u_{*}}{U_{\mathrm{s}}}\right)^{1 / 2}$,

where $U_{\mathrm{s}}$ is the Stoke drift velocity. $L a=0.35$ (McWilliams et al., 1997) or $L a=0.4$ (Belcher et al., 2012) are common values for well-developed sea and show a dominance of Langmuir circulation over wind-forced production. The transition between those two regimes can be set for $L a=0.7$ (Belcher et al., 2012). The second ratio is computed $h / L_{\mathrm{L}}$, where $h$ is the mixed layer depth and $L_{\mathrm{L}}$ is the Langmuir stability length:

$L_{\mathrm{L}}=\frac{-w_{* \mathrm{~L}}}{J_{\mathrm{b}}}$

where $J_{\mathrm{b}}$ is the buoyancy flux as computed in Sect. 2.1 and $w_{* \mathrm{~L}}$ is the scaling for wind and wave-forced turbulence (Kantha and Clayson 2000, Kantha et al., 2010):

$w_{* \mathrm{~L}}=\left(u_{*}^{2} U_{\mathrm{s}}\right)^{1 / 3}$

where $U_{\mathrm{s}}$ is the Stokes drift computed as described in Sect. 2.2.

\section{Yoyo casts and turbulence observations}

Microstructure profiles were collected form a free-falling profiler and hence the surface layer (roughly $2 \mathrm{~m}$ ) was lost. Moreover, the usual practice in processing microstructure casts is to ignore depths up to twice the vessel draft in order to avoid contamination from the turbulent ship wake. However, TKE dissipation profiles will be shown cutting off only the first $5 \mathrm{~m}$ (roughly the vessel draft) because, even if noisy and not scaling well with the available forcing, data collected from 5 to $10 \mathrm{~m}$ can still give some information on the magnitude of the surface TKE production and on its transfer to deeper layers of the shallow GoT.

In the CARPET2014 data set the observed TKE dissipation scaled as expected with the exception of a surface layer that can reach as deep as $10 \mathrm{~m}$ (as TKE dissipation rate profiles in Fig. 9 will show), this mismatch can be attributed to the complex forcing of surface turbulence. Figure 5 shows the regime diagram of turbulence forcing at the VIDA buoy computed every half an hour. A reduced time series (from 2 February 00:00 UTC to 4 February 12:00 UTC) had to be chosen since it was the only period covered by the shipborne WASS observations, used to verify the JONSWAP spectrum, and of almost constant wind forcing. Up to the end of Y03 (3 February at 12:00 UTC, green squares in Fig. 5) turbulence generation was dominated by wave forcing with some contribution from wind shear and a growing importance of buoyancy (the ratio $h / L_{\mathrm{L}}$ is slowly increasing). The orange squares represent values between the end of Y03 and 4 February at 12:00 UTC and show a progressive weakening of all forcing with buoyancy decreasing to a lesser extent and hence defining a dominance of convection in TKE generation.

The regime diagram of Fig. 5 gives, as a general picture, a condition in which the role of buoyancy in TKE generation changes significantly ( $h / L_{\mathrm{L}}$ varies between 0.16 to 7.95$)$, reaching a quasi-dominance after Y03. Instead the values of $L a$ present much smaller variations (between 0.47 and 0.55 ), 


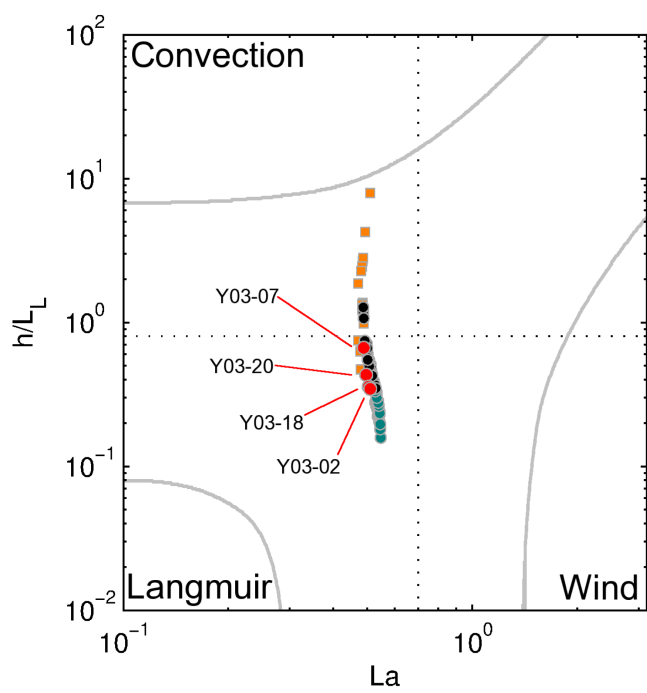

Figure 5. Regime diagram of turbulence forcing computed at the VIDA buoy from 2 February (14:30 UTC) to 4 February (12:00 UTC). Green and orange squares represents values before and after the Y03, red marks are the values for the ensembles shown in Fig. 9. The horizontal dashed line indicates the demarcation between convection dominated turbulence and shear stress dominated one; the vertical dashed line shows demarcation between conventional wind stress-driven turbulence and Stokes production-driven one.

meaning that the relative contribution of wind and waves is almost constant throughout observations with a stronger role of the latter. During the following analysis, we will show the similarity scaling for wind shear and buoyancy but not for waves, due to the fact that no wave field observations were collected during the yoyo casts. Moreover, using the probe in a free-falling configuration we do not have information on the layer under direct influence of wave TKE production. Similarly not enough observations were collected to describe the eventual insurgence of Langmuir circulation. Hence, as will be discussed for Fig. 9, there is a significant disagreement between the observed profiles and the similarity scaling for the upper $10 \mathrm{~m}$; this can be explained by the role of waves and wave-current interaction in generating and distributing turbulence. In this work we focus on the role of bottom intrusions with different turbidity in suppressing turbulence and hence we leave a thorough description of the surface condition to future studies.

Yoyo cast Y01 was located in a shallower part of the GoT closer to the coast (Fig. 1, red square in left panel). It presented a completely mixed water column with no visible stratification, just a small increase in temperature (less than $0.2{ }^{\circ} \mathrm{C}$ ) and a decrease in salinity (about 0.1 ) toward the end of the yoyo series (Fig. 6). During sampling, surface salinity (well over 37) shows no influence from the Isonzo River; turbidity levels, however, were significantly high, in the range of 22.6 to 23.5 FTU. TKE dissipation rate profiles showed high

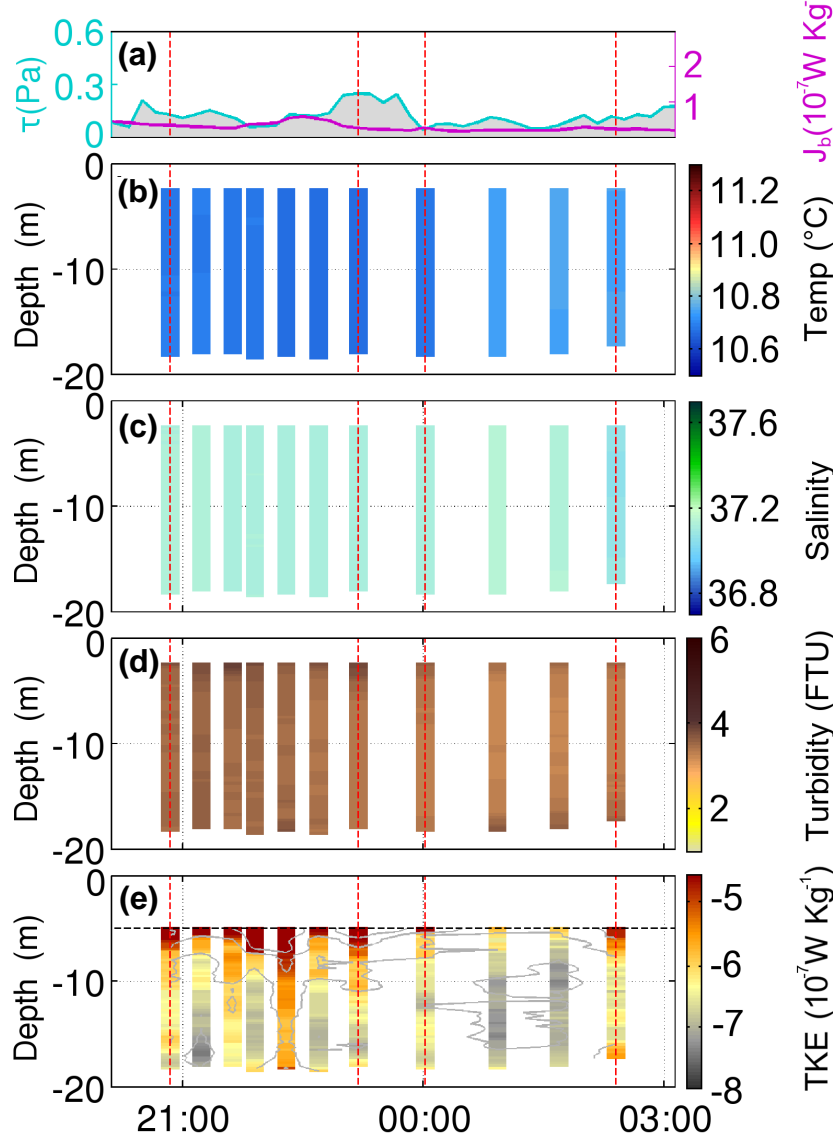

Figure 6. Hovmöller diagrams for Y01: (a) wind stress and buoyancy flux during the $\mathrm{Y} 01$, (b) temperature profiles, (c) salinity profiles, (d) turbidity profiles in FTU, (e) turbulent kinetic energy dissipation rate in logarithmic scale (contours spaced in log of $1 \mathrm{~W} \mathrm{~kg}^{-1}$ ). Red dashed lines show the time of collection of the Y01 casts reported in top panels of Fig. 8.

values near the sea surface, which progressively decreased to values of the order of $10^{-6} \mathrm{~W} \mathrm{~kg}^{-1}$ near the bottom, with one exception being the cast Y01-05 (fifth ensemble of yoyo Y01) in which $\varepsilon$ values were high throughout the water column. ADCP-measured currents (Fig. 7, lower panel green line) showed generally low bottom currents of magnitudes below $0.1 \mathrm{~m} \mathrm{~s}^{-1}$ with an increase toward the end of observations to values smaller than $0.2 \mathrm{~m} \mathrm{~s}^{-1}$. This can be explained by the change in tidal regime from falling to rising tide and is also reflected in the $\varepsilon$ profiles that show an increase near the sea floor for the last ensembles of the series. The shallower cell (Fig. 7, upper panel green line) presents a similar condition, with two peaks of magnitude just less than $0.2 \mathrm{~m} \mathrm{~s}^{-1}$ but without an increasing trend during sampling. Current directions (Fig. 7, black lines) are more complex, with dominant direction from the east for the surface cell, and from the south-west for the bottom cell. 

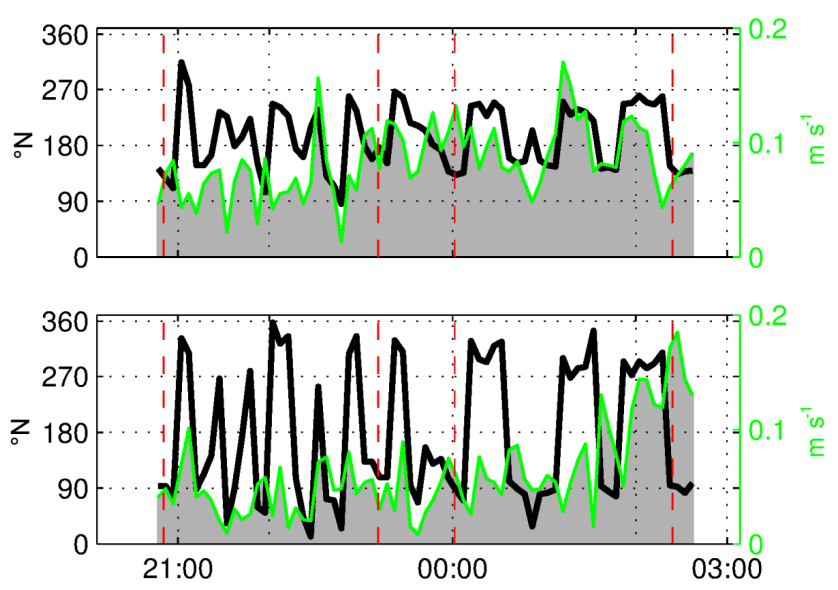

Figure 7. Y01 ADCP currents: second (top panel) and third (bottom panels) cells of Y01 ADCP currents. The cell centres are located at 13 and $17 \mathrm{~m}$ below sea surface; cell width is $4 \mathrm{~m}$. Black lines show current direction in degrees (due north) and green lines show current magnitude in $\mathrm{ms}^{-1}$. Red dashed lines show the time of collection of the Y01 casts reported in top panels of Fig. 8.

The TKE dissipation rate profiles support the measurements just described and are in agreement with the local forcing (Fig. 8). In the case of Y01-01 and Y01-07, both characterized by strong wind forcing, a surface layer of about $8 \mathrm{~m}$ in which TKE dissipation rates fall to $10^{-6} \mathrm{~W} \mathrm{~kg}^{-1}$ can be identified, while near the sea floor, the bottom shear stress did not influenced the TKE dissipation rate much. The Y0108 ensemble was collected under weak winds and the surface layer, with marked TKE dissipation rate drop, was shallower (just $5 \mathrm{~m}$ ). The last ensemble of the series (Y01-11) was collected during rising tide with bottom currents up to $0.2 \mathrm{~m} \mathrm{~s}^{-1}$ and moderate wind stress. This is reflected in the TKE dissipation rate profile with a decrease in depth in the first $10 \mathrm{~m}$ and then a marked increase in the last $5 \mathrm{~m}$, due to the influence of turbulence generated by the bottom shear stress. In all casts, the contribution of buoyancy-generated turbulence is weak $\left(\varepsilon_{\mathrm{b}}\right.$, magenta dashed line in Fig. 8) since the buoyancy flux is low and the Monin-Obukhov length scale is very large (negative), larger than the local sea floor depth (Fig. 2d). Y01 profiles show that in the absence of water column stratification, the $\varepsilon$ profile is mostly defined by the surface wind and bottom stresses.

Yoyo casts Y02 and Y03 were located at the same site (Fig. 1, blue square) but roughly 2 days apart from each other and present significant differences in both water column structure and $\varepsilon$ profiles. The water column during Y02 (Fig. 9) was always stratified, at the beginning of the casts with colder and fresher waters at the surface (consistent with the influence of the Isonzo River discharges, as hinted by high turbidity), then with warmer and saltier intrusion near the sea floor. Higher suspended sediment concentrations were observed at the bottom at the beginning and towards the end of the yoyo. Apart from the surface layer, the TKE dissipation rate was generally low from mid-depths to the sea floor with values almost at noise level ( $\varepsilon$ values lower than $10^{-8} \mathrm{~W} \mathrm{~kg}^{-1}$ ), but increased by 2 orders of magnitude around 18:00 UTC on 1 February and then decreased again to very low values. ADCP currents (Fig. 10) at bottom (ADCP cell 3 centred at $13 \mathrm{~m}$ depth, lower panel) and mid-depths (ADCP cell 2 centred at $9 \mathrm{~m}$ depth, top panel) were similar, with water flowing to the north-east (current speed up to $0.2 \mathrm{~m} \mathrm{~s}^{-1}$ ) during a rising tide up to around 20:00 UTC. Once the tidal phase changes to falling tide, currents turn toward the south-east, with an abrupt change in the bottom layer, and drop to values below $0.05 \mathrm{~m} \mathrm{~s}^{-1}$.

In contrast to the Y01 data set, the Y02 ensembles had a more complex behaviour due to the presence of surface stratification, the incoming water bottom intrusion and the change in tidal character. Casts Y02-01 and Y02-04 (Fig. 8, middle panels) had a similar water column structure, with fresher and cooler waters at the surface and more turbid waters near the sea floor. The surface wind stress was weak during both casts and a steep drop of $\varepsilon$ to values below $10^{-6} \mathrm{~W} \mathrm{~kg}^{-1}$ can be seen around $7 \mathrm{~m}$ depth. Below this depth, the two $\varepsilon$ profiles diverge due to different bottom current velocities. In Y02-01, $\varepsilon$ falls to noise level due to a slower bottom current (and hence low bottom shear stress). In contrast, Y02-04 was characterized by higher wind stress with a TKE dissipation rate significantly higher, reaching values above $10^{-6} \mathrm{~W} \mathrm{~kg}^{-1}$ with a profile that closely follows the $\varepsilon_{\mathrm{sb}}$. In the second half of the yoyo series, wind speed increased up to values around $10 \mathrm{~m} \mathrm{~s}^{-1}$, which results in a deepening of the $\varepsilon$ drop from 7 to 10 and $15 \mathrm{~m}$ in Y02-06 and Y02-10, respectively. Y02-06 has a bottom current velocity close to that of Y02-04 but $\varepsilon$ reaches lower values at the bottom due to the damping effect of the incoming water mass intrusion.

A more extreme case of an abrupt drop in TKE dissipation rate near the sea floor was Y02-10, in which $\varepsilon$ reached noise levels just $5 \mathrm{~m}$ above the sea floor. This was the result of a concurrence of two factors. On the one hand, a sudden drop in bottom current velocity can be related to the change in the tidal character (that results in a lower $\varepsilon_{\mathrm{sb}}$ ). On the other hand, a different water mass (warmer, saltier and with high concentrations of suspended sediments) intruded in the bottom layer and acted as a physical barrier to the propagation of wind-generated turbulence to the bottom part of the water column. The turbulence generated by buoyancy flux was low throughout Y02 with the exception of the first ensembles, as shown by the small Monin-Obukhov length (Fig. 2).

Y03 (Fig. 9, right panels) presented a water column cooler and fresher than Y02 with values closer to Y01. No surface salinity stratification was observed as a result of the strong Bora winds that pushed the Isonzo plume out of the GoT along its northern shore and enhanced vertical mixing to a point in which the water column was completely mixed (i.e. Y03-07). Moreover, the Isonzo discharges during Y03 presented a decrease in magnitude from the flood event (mean discharge $500 \mathrm{~m}^{3} \mathrm{~s}^{-1}$ ) lasting between noon of 3 February 

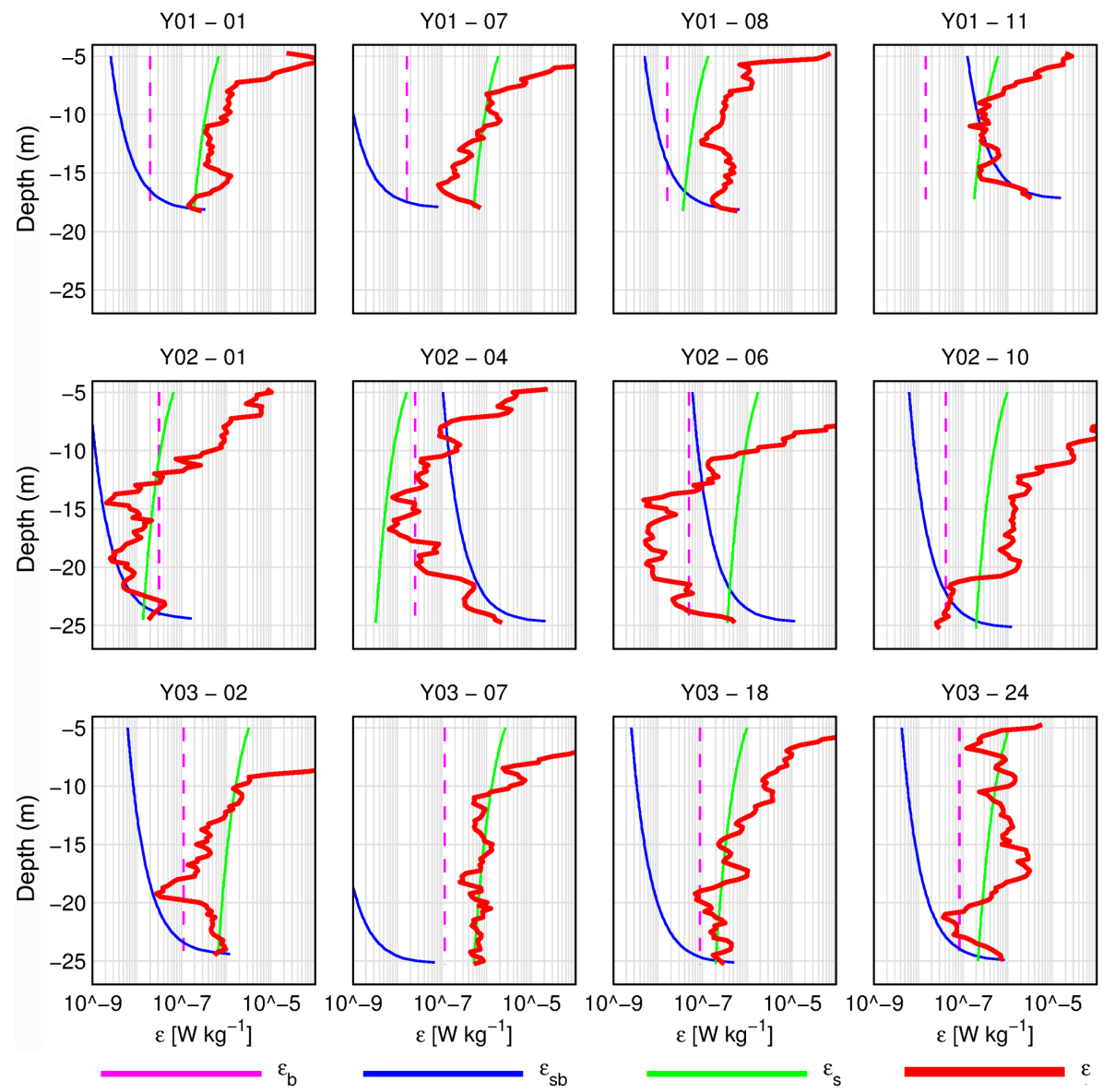

Figure 8. Similarity scaling of turbulent kinetic energy dissipation rate $(\varepsilon)$ for four representative casts for each yoyo, Y01 top panels, Y02 central panels and Y03 bottom panels. For each cast the observed TKE dissipation rate is shown $(\varepsilon$, thick red line), and the turbulence generated by surface wind stress $\left(\varepsilon_{\mathrm{s}}\right.$, green line), bottom shear stress $\left(\varepsilon_{\mathrm{sb}}\right.$, blue line) and buoyancy flux ( $\varepsilon_{\mathrm{b}}$, magenta vertical dashed line).

and 4 February. During Y03 two intrusions were observed near the bottom, one right at the beginning of the series ending at about 16:00 UTC and one starting around 00:00 UTC and lasting for the remaining part of the yoyo. Even though those intrusions involve water masses of similar temperature and salinity, they were significantly different in turbidity, with the first intrusion carrying more suspended sediments than the second one. This can be partially attributed to current speed and direction, with the first intrusion flowing southwest at velocities higher than $0.1 \mathrm{~m} \mathrm{~s}^{-1}$ and the second one due east at a much lower speed (Fig. 10), with water properties consistent with an open-sea origin as shown in Fig. 5. It is of interest to note the abrupt change in current direction around 00:00 UTD right at the beginning of the second intrusion, which also points toward a different origin of this water mass.

Y03 TKE dissipation rates were generally higher than those of Y02 throughout the series. Y03-01 had a stratified water column with gradients across the pycnocline similar to those of Y02-10, with a mixed surface layer and with intruded turbid and dense water at the bottom. Below the mixed surface layer, the $\varepsilon$ value dropped to almost $10^{-8} \mathrm{~W} \mathrm{~kg}^{-1}$ at the top of the intrusion $(20 \mathrm{~m})$ and then abruptly rose back to values of the order of $10^{-6} \mathrm{~W} \mathrm{~kg}^{-1}$ as a consequence of high bottom currents (Fig. 8). In the case of Y03-07, there is no intrusion and the water column is fully mixed, so that the $\varepsilon$ profile after decreasing in the surface layer stayed around $10^{-6} \mathrm{~W} \mathrm{~kg}^{-1}$ also near the sea floor (i.e. no significant influence of $\varepsilon_{\mathrm{sb}}$ ). In the second part of the yoyo series (Y03-18 and Y03-20), the intruding water mass in contrast to Y03-01 and Y02-10, was not enhanced by a high suspended sediment load and hence the TKE dissipation rate was still damped by density interface but to a lesser degree than in the other cases.

\section{Summary and discussion}

Between the end of January and the first week of February 2014, during a period of high river discharges and moderate wind forcing, we were able to make the very first microstructure measurements in the Gulf of Trieste (Fig. 8, middle panels, and Fig 9, left panels). These observations, 

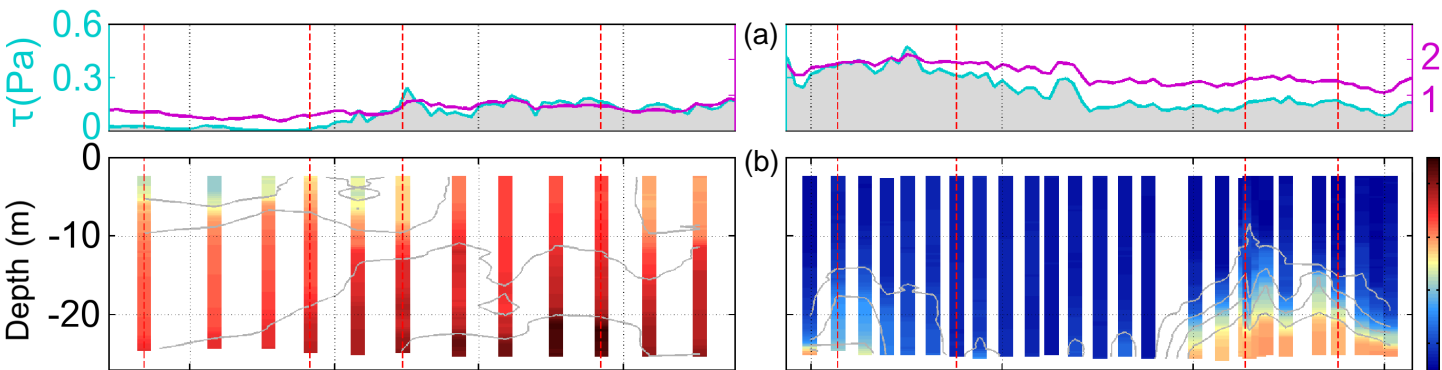

(b)
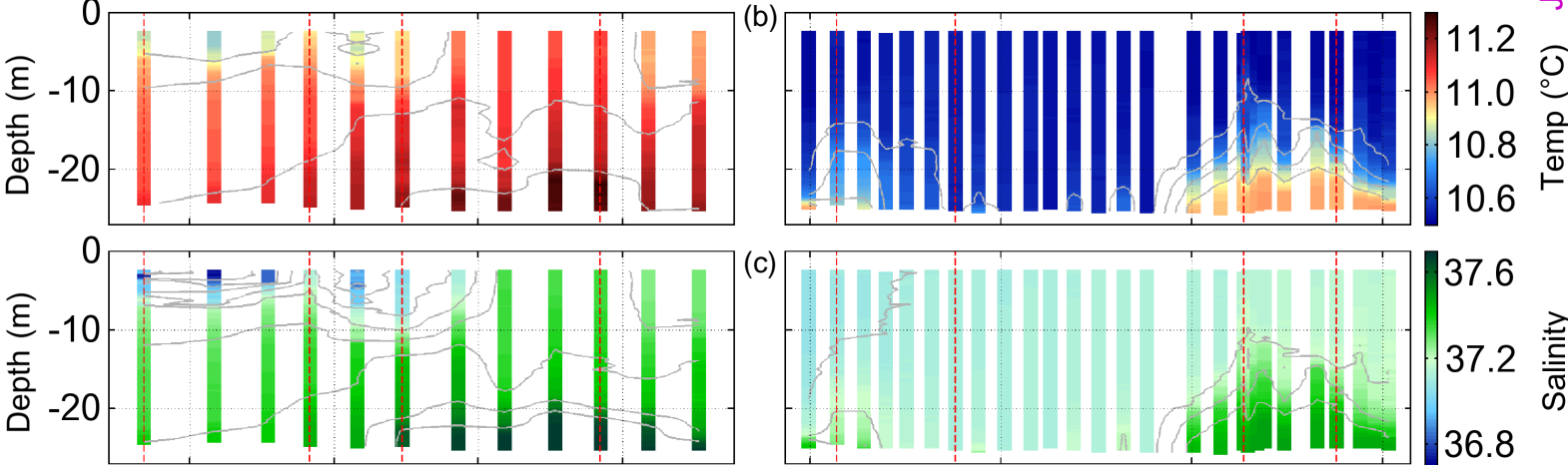

37.6
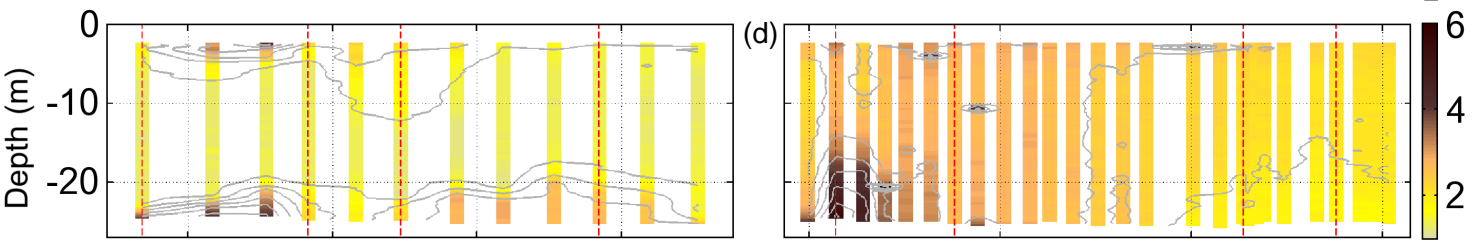

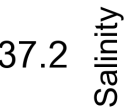
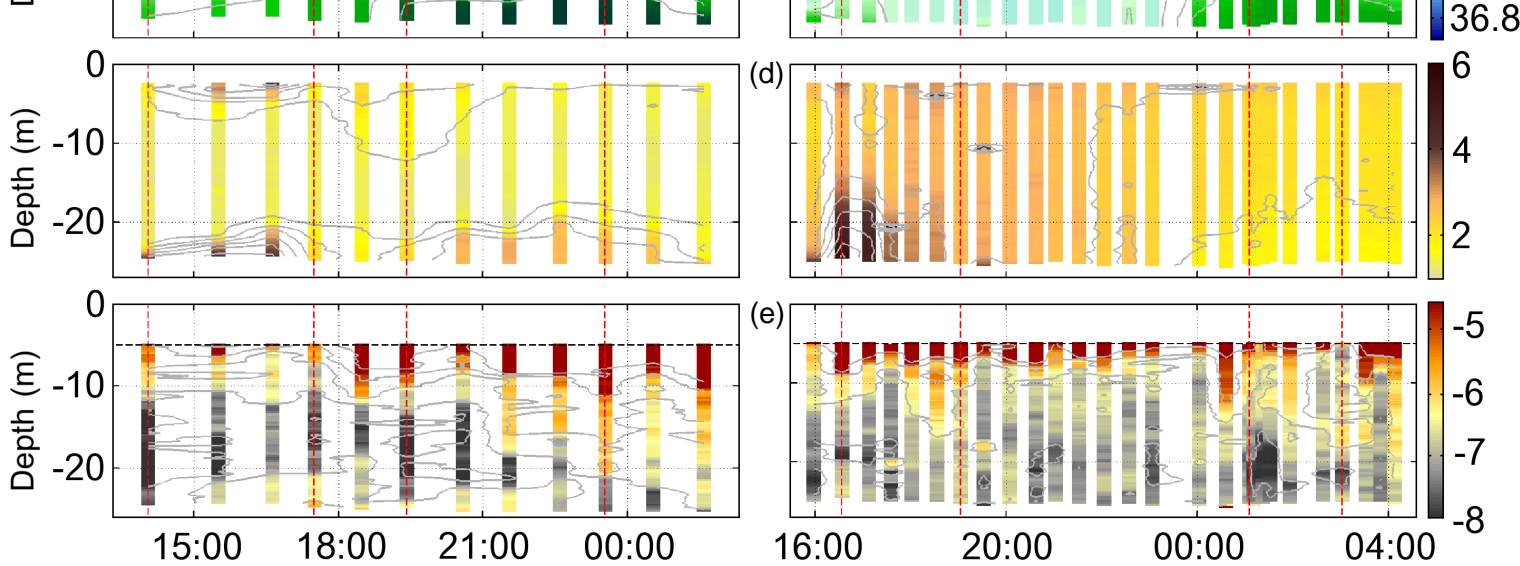

Figure 9. Hovmöller diagrams of Y02 (left) and Y03 (right). Panels shows (a) wind stress (cyan) and buoyancy flux (magenta), (b) temperature profiles (grey contours are spaced $0.1^{\circ} \mathrm{C}$ ), (c) salinity profiles (grey contours are spaced 0.1 ), (d) turbidity profiles in FTU (grey contours are spaced 1 FTU) and (e) turbulent kinetic energy dissipation rate in logarithmic scale (contours spaced in log of $1 \mathrm{~W} \mathrm{~m}^{-2}$ ). Red dashed lines show the time of collection of the yoyo casts reported in Fig. 8.

along with CTD casts, ADCP currents and meteorological measurements, provided a comprehensive picture of the effect of different forcing and water masses on the penetration of turbulence from its source regions and on mixing in the water column.

The CARPET2014 data set analysis shows a winter circulation inside the GoT driven mostly by wind, tides and the Isonzo River plume. As expected, a significant correlation was found between the bottom circulation, and the wind and tidal forcing. During strong wind periods, such as during Y02 or the beginning of Y03, bottom currents increased in magnitude, while during weaker winds, such as the beginning of Y02 and the end of Y03, they tended to decrease. Near the sea floor, two types of bottom water intrusions were identified: the first one coming from the northern Adriatic coastal area during Y02 and the second one from the open sea in front of the Po Delta during Y03. Those intrusions present similar densities but different physical properties (i.e. temperature and salinity) and suspended sediment concentration. Moreover, their arrival in the GoT followed periods domi- nated by different wind forcing, mostly Scirocco for the first intrusion and Bora for the second.

Apart from the surface layer, the TKE dissipation rates follow the similarity scaling for wind stress-generated turbulence and for the one due to bottom shear stress near the sea floor (Fig. 8). Buoyancy-driven turbulence under those conditions proved to be generally insignificant, as shown by the Monin-Obukhov length scale being generally greater than the sea floor depth.

The $\varepsilon$ profiles of Fig. 8 and the water column properties shown in Figs. 6 and 9 can help in defining a general description of the impacts of density interfaces on the TKE dissipation rate in the water column.

- Well-mixed water column: the TKE dissipation rate profile, below the surface layer, is solely defined by its forcing. Examples of this are the Y01 ensembles, in which the $\varepsilon$ profiles closely follow the scaling both in the middle of the water column and at depth (Fig. 8, top panels), 

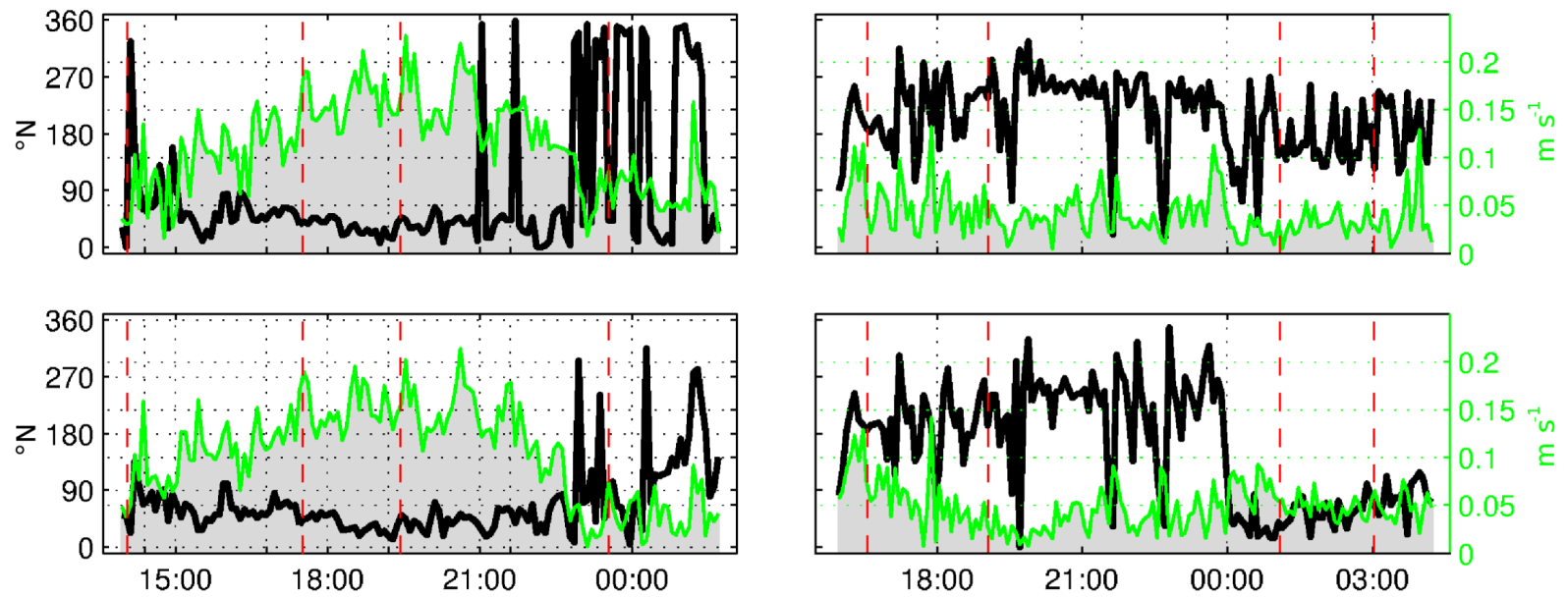

Figure 10. Second (top panel) and third (bottom panels) cells of ADCP currents. The cell centres are located at 13 and $17 \mathrm{~m}$ below sea surface; cell width is $4 \mathrm{~m}$. Black lines show current direction (due north) and green lines show current magnitude in $\mathrm{m} \mathrm{s}^{-1}$. Left panels show Y02, right panels Y03. Red dashed lines show the time of collection of the yoyo casts reported in Fig. 8.

and the Y03-07 ensemble, which presented an almost constant TKE dissipation rate below the surface layer.

- Surface stratification: in presence of a stronger surface density interface (i.e. casts Y02-01 and Y02-04), turbulence is confined to the shallow surface layer with low $\varepsilon$ values in the rest of the water column, whether bottom currents are low (Y02-01) or with an increase in $\varepsilon$ in presence of strong bottom currents (Y02-04). It is noteworthy that in both cases the bottom turbidity was high but not able to damp turbulence in the absence of a density interface.

- Dense bottom intrusion with turbidity gradient: when a turbidity gradient is also present at a density interface the damping effect on turbulence is significantly enhanced as in Y02-06, Y03-02 and Y02-10. In the first two ensembles an increase of $\varepsilon$ was observed due to a strong bottom current, which was not present during Y02-10, hence the sudden drop of $\mathrm{O}(2)$ in $\varepsilon$ just below the density and turbidity interface.
- Dense bottom intrusion without any turbidity gradient: the presence of a density interface at the bottom produces a gradual damping of turbulence (Y03-18 and Y03-20). In this case, there is no significant difference in turbidity between the intrusion and the ambient waters and hence $\varepsilon$ is decreased but to a lesser degree than in the previous case.

The general picture that can be drawn from these results is that the water column structure (both the presence of buoyancy and suspended sediments gradients) plays a fundamental role in defining the TKE dissipation rate, not only inside the water column but also in the proximity of the sea floor. In the specific case of the GoT, under moderate wind forcing, the presence of the intruding Adriatic waters can be a significant limitation on complete mixing of the water column. 


\section{Appendix A}

The traditional approach in processing microstructure profiles calls for averages of repeated casts (when logistically feasible three or more) at each station, to reach statistical significance and increase the accuracy. The averaging produces meaningful results for the mean profiles and yields quantities more representative of the turbulence in the water column. However, cases in which the water column has strong stable density interfaces moving up and down are exceptions. In those cases, turbulence and other parameters differ from one cast to another in their vicinity. In the CARPET2014 data set, changes in the interface depth between casts were as much as $4 \mathrm{~m}$. This means that by averaging measured quantities at fixed depths over consecutive profiles, the averages get smeared, and hence characterized by smoother gradients and broader peaks. To avoid this, an ad hoc algorithm was developed using the central profile of each ensemble as reference and realigning sections of the remaining profiles to it. The mean profile was then obtained by averaging the central profile with the realigned sections. The step-by-step procedure applied to two consecutive vertical profiles, is as follows:

1. One profile is chosen as the reference (Fig. A1a, cyan) and the other as the one to be realigned (Fig. A1a, black).

2. Starting from the surface, the correlation coefficients are computed for a progressively longer section, until the full profiles (i.e. surface to bottom) are accounted for. Starting from the surface, the section with the maximum correlation value is considered as a "surface layer" that does not need to be shifted. In Fig. A1c, its lower limit is the horizontal red line.

3. The root mean square error for the remaining parts of the profiles is then computed with a 5-point moving window (Fig. A1c black line) and the maximum peaks are found (Fig. A1c red dots). If the two peaks are closer than 10 points to each other, just the largest one is considered. The 10-point window was chosen because in a sensitivity test (not shown), it proved to be the most efficient in separating the two peaks. The two peaks are then used to identify the sections to realign. The limit of each section is set at the mid-point between two peaks (red line, in Fig. A1c).
4. Each section of the profile to be realigned is then correlated to the reference profile shifting it from +20 to -20 points. The shift with maximum correlation is then taken as the needed shift. In Fig. A1d, the reference profile is in cyan, the one to be shifted in black and the shifted sections are in red.

The process is repeated for each successive cast at the station and then the averages are computed over the new shifted profiles and the reference one. The final result of the process is shown in Figure A1e and A1f. Figure A1 also presents the same plots but for $\varepsilon$.

The method described above offers a more meaningful vertical distribution of the TKE dissipation rate, by taking into account the vertical oscillations of the pycnocline, since turbulence is extinguished in the vicinity of strongly stable interfaces. As a consequence, in the vertically shifted profiles, the peaks in the TKE dissipation rate are much clearer and better represent the shape of the observed profiles. The peaks are just above the thermocline. In general, when more than one cast is collected at a station, the most conservative assumption is to consider the central profile as the reference one for the water column structure. Other profiles over the cycle are then realigned with respect to the reference profile to obtain the TKE dissipation rate caused by vertical shear, uncontaminated by the zero values right at the interface. 
(a)

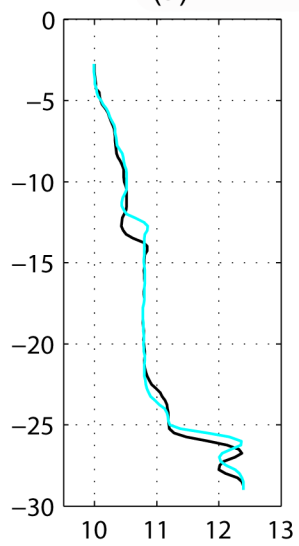

(b)

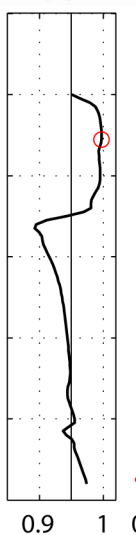

(c)

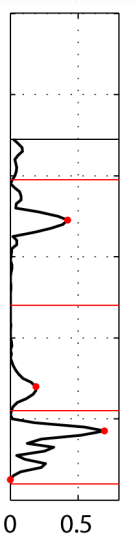

(d)

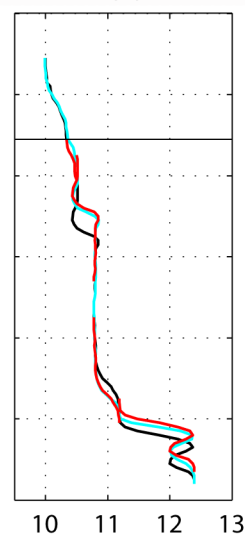

(e)

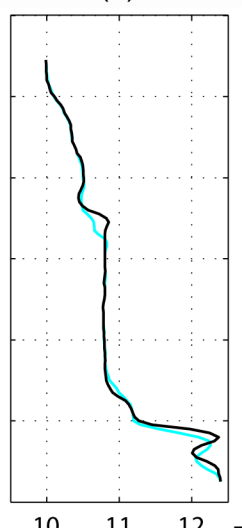

(f)

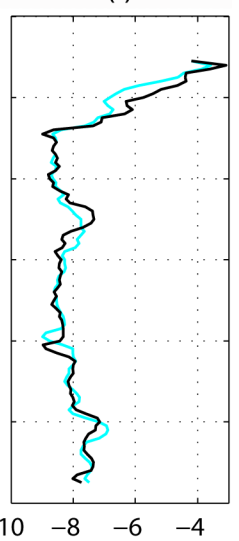

Figure A1. (a) Original temperature profiles used in the realignment algorithm: reference in cyan, profile to be realigned in black. (b) Correlation coefficient computed for progressively longer segments starting form surface. The black vertical line is the 0.95 correlation threshold and the red circle the maximum correlation. (c) Root mean square error between the two profiles; red dots identify peaks. Black horizontal lines divide the segments used for realignment. (d) The realigned segments (thin red lines) above the two original profiles. Panels (e) and (f) show the mean profile for temperature and turbulent kinetic energy dissipation rates computed using the original profiles (cyan) and the realigned ones (black). 
Acknowledgements. The authors thank CNR-UPO for having granted R/V Urania ship time, and the vessel crew for their kind cooperation is thanked for their kind cooperation. CARPET2014 campaign was supported by the Flagship Project RITMARE The Italian Research for the Sea - coordinated by the Italian National Research Council and funded by the Italian Ministry of Education, University and Research within the National Research Program 2011-2013. This work was also supported by the FP7 project COCONET (grant agreement no: 287844) of the European Commission.

Edited by: J. Wolf

\section{References}

Anis, A. and Moum, J. N.: Surface wave-turbulence interactions: Scaling (z) near the sea surface, J. Phys. Oceanogr, 25, 20252045, 1995.

Benetazzo, A., Fedele, F., Gallego, G., Shih, P.-C., and Yezzi, A.: Offshore stereo measurements of gravity waves, Coast. Eng., 64, 127-138, 2012.

Benetazzo, A., Graham, L., and Carniel, S.: Mapping Coastal Frontal Zones In Northern Adriatic via AUV, Sea Tech., 56, 1921, 2015.

Belcher, S. E., Grant, A. L. M., Hanley, K. E., Fox-Kemper, B., Van Roekel, L., Sullivan, P. P., Large, W. G., Brown, A., Hines, A., Calvert, D., Rutgersson, A., Pettersson, H., Bidlot, J.-R., Janssen, P. A. E. M., and Polton, J. A.: A global perspective on Langmuir turbulence in the ocean surface bounday layer, Geophys. Res. Lett., 39, L18605, doi:10.1029/2012GL052932, 2012.

Burchard, H., Craigb, P. D., Gemmrichc, J. R., van Harend, H., Mathieue, P.-P., Meierf, H. E. M., Smithg, W. A. M. N., Prandkeh, H., Rippethi, T. P., Skyllingstadj, E. D., Smythj, W. D., Welshk, D. J. S., and Wijesekeraj, H. W.: Observational and numerical modeling methods for quantifying coastal ocean turbulence and mixing, Prog. Oceanogr., 76, 399-442, 2008.

Carniel, S., Sclavo, M., Kantha, L., and Prandke, H.: Doublediffusive layers in the Adriatic Sea, Geophys. Res. Lett., 35, L02605, doi:10.1029/2007GL032389, 2008.

Carniel, S., Kantha, L. H., Book, J. W., Sclavo, M., and Prandke, H.: Turbulence variability in the upper layers of the Southern Adriatic Sea under a variety of atmospheric forcing conditions, Cont. Shelf Res., 44, 39-56, 2012.

Comici, C. and Bussani A.: Analysis of the River Isonzo discharge (1998-2005), Bolletino di Geofisica Teorica ed Applicata, 48, 435-454, 2007.

Csanady, G. T.: Circulation in the Coastal Ocean, 279 pp., D. Reidel, Dordrecht, 1982.

D'Asaro, E.: Turbulence in the upper-ocean mixed layer, Annu. Rev. Mar. Sci., 6, 101-115, 2014.

Falcieri, F. M., Benetazzo, A., Scalvo, M., Russo, A., and Carniel, S.: Po River plume pattern variability investigated from model data, Cont. Shelf Res., 87, 84-95, doi:10.1016/j.csr.2013.11.001, 2013.

Fairall, C., Bradley, E., Hare, J., and Grachev, A.: Bulk parameterization of Air-Sea fluxes: updates and verification for the COARE algorithm, J. Climate, 16, 571-591, 2003.
Gargett, A. E.: "Theories" and techniques for observing turbulence in the euphotic zone, Sci. Mar., 6(suppl. 1), 24-45, 1997.

Grant, L. A. and Belcher, S. E.: Characteristics of Langmuir turbulence in the ocean mixed layer, J. Phys. Oceanogr., 39, 18711997, 2009.

Gregg, M. C.: Dynamic mixing in the thermocline: a review, J. Geophys. Res., 32, 5249-5286, 1987.

Hasselmann, K.: Wave-driven inertial oscillations, Geophys. Fluid Dyn., 45, 55-62, 1970.

Hasselmann, K., Barnett, T. P., Bouws, E., Carlson, H., Cartwright, D. E., Enke, K., Ewing, J. A. Gienapp, H., Hasselmann, D. E., Kruseman, P., Meerburg, A., Müller, P., Olbers, D. J., Richter, K., Sell, W., and Walden, H.: Measurements of wind-wave growth and swell decay during the Joint North Sea Wave Project (JONSWAP), Deutches Hydrographisches Institut, 1973.

Kantha, L. K.: Turbulent entrainment at a buoyancy interface due to convective turbulence, in: Fjord Oceanography, edited by: Freeland, H. J., Farmer, D. M., and Levings, C. D., Plenum Press, 205-2015, 1980.

Kantha, L.: Modeling turbulent mixing in the global ocean: second moment closure models, in: Turbulence: Theory, Types and Simulation, edited by: Marcuso, R. J., Nova Science Publishers, $1-68,2010$.

Kantha, L. H. and Clayson, C. A.: Small Scale Processes in Geophysical Fluid Flows, Academic Press, vol. 67, 2000.

Kantha, L. H. and Clayson, C. A.: On the effect of surface gravity waves on mixing in the oceanic mixed layer, Ocean Modell., 6, 101-124, 2004.

Kantha, L., Lass, H. U., and Prandke, H.: A note on Stokes production of turbulence kinetic energy in the oceanic mixed layer: observations in the Baltic Sea, Ocean Dyn., 60, 171-180, 2010.

Li, M., Gargett, C., and Skyllingstad, E.: A regime diagram for classifying turbulent large eddies in the upper ocean, Deep-Sea Res. Pt.I, 52, 259-278, 2005.

Malačič, V., Celio, M. and Naudin, J. J.: Dynamics of the surface water in the Gulf of Trieste (Northern Adriatic) during drifting experiments, paper presented at Ecosystem research report No 32 - the Adriatic Sea - Proceedings of the workshop 'Physical and biogeochemical processes in the Adriatic Sea', Office for Official Publications of the European Communities, Luxembourg, Portonovo, Italy, 23-27 April 1996.

Malačič, V. and Petelin, B.: Gulf of Trieste, in Physical Oceanography of the Adriatic Sea, Past, present and Future, edited by: Cushman-Roisin, B., Gačić, M., Poulain, P.-M., and Artegiani, A., 167-177, Kluwer Academic Press, Dordrecht, 2001.

Malačič, V., Petelin, B., and Vodopivec, M.: Topographic control of wind-driven circulation in the northern Adriatic, J. Geophys. Res., 117, C06032, doi:10.1029/2012jc008063, 2012.

McWilliams, J. C., Sullivan, P. P., and Moeng, C. H.: Langmuir turbulence in the ocean, J. Fluid. Mech., 94, 6273-6284, 1997.

Paskyabi, M. B. and Fer, I.: Turbulence structure in the upper ocean: a comparative study of observations and modelling, Ocean Dynam., 64, 611-631, 2014.

Peters, H. and Orlić, M.: Turbulent mixing in the springtime central Adriatic Sea, Geofizika, 22, 1-19, 2005.

Peters, H., Craig, M. L., Orlić, M., and Dorman, C. E.: Turbulence in the wintertime northern Adriatic Sea under strong atmospheric forcing, J. Geophys. Res., 112, C03S09, doi:10.1029/2006JC003634, 2007. 
Prandke, H. and Stips, A.: Test measurements with an operational microstructure-turbulence profiler: Detection limit of dissipation rates, Acqua Sci., 60, 191-209, 1998.

Prandke, H., Holtsch, K., and Stips, A.: MITEC Report Technical Note No. I.96.87, European commission, Joint Research Center, Sapce applications Institute, ISPRA/Italy, 2000.

Ricchi, A., Miglietta, M. M., Falco, P. P., Benetazzo, A., Bonaldo, D., Bergamasco, A., Sclavo, M., and Carniel, S.: On the use of a coupled ocean-atmosphere-wave model during an extreme cold air outbreak over the Adriatic Sea, Atmos. Res., 172-172, 48.65, 2016.

Shay, T. J. and Gregg, M. C.: Turbulence in an oceanic convective mixed layer, Nature, 310, 282-285, 1984.
Shay, T. J. and Gregg, M. C.: Convectively driven turbulent mixing in the upper ocean, J. Phys. Oceanogr., 16, 1777-1798, 1996.

Simpson, J. H., Bos, W. G., Shirmer, F., Souza, A. J., Rippeth, T. P., Jones, S. D., and Hydes, D.: Periodic stratification in the Rhine ROFI in the North Sea, Oceanologica Acta, 16, 23-32. 1993.

Teixieira, M. A. C. and Belcher, S. E.: On the structure of Langmuir turbulence, Ocean Model., 9, 597-608, 2010.

Thorpe, S. A.: The Turbulent Ocean, Cambridge University Press, Cambridge, UK, 439 pp., 2005. 